\title{
Construction of a Collaborative Platform for Innovation Teaching Based on SNS
}

\author{
Ting Shu ${ }^{a}{ }^{*}$, Mangmang $\mathrm{Gu}^{\mathrm{b}}$, Jinsong $\mathrm{Xia}^{\mathrm{c}}$ and Jinyu Song ${ }^{\mathrm{d}}$ \\ School of Information Science and Technology, Zhejiang Sci-Tech University, \\ Hangzhou 310018, China \\ ashuting@zstu.edu.cn, ’bmangmanggu@163.com, \\ cjs_xia@126.com, dsongjinyu@zstu.edu.cn
}

Keywords: SNS; Innovation Practice; Collaborative Platform; Smart Mobile Application

\begin{abstract}
The innovative spirit and practical ability are graduates' core competitiveness of employment. A innovative teaching mode can facilitate the promotion of the innovation capability of college students, based on the collaborative teaching activities between students, teachers on campus and engineers off campus. However, at present, there is still lack of effective support software platform for collaborative practice teaching. In this paper, we present an approach for constructing such a platform based on Social Networking Services (SNS) and mobile client applications. Using SNS, this system enables learners and instructors to easily organize their creative activities. In addition, participants of creative activities can more effectively interact with each other, commit themselves to collaborative teaching and learning, relying on the platform's smart mobile application.
\end{abstract}

\section{Introduction}

In today's competitive environment, university graduates' innovative practice capability plays a key role during their future job-hunting. In a job interview, an employer may pay more attention on a graduate's potential for innovation practice, instead of the number of their learned courses. Hence, how to cultivate university students to acquire innovation capability preparing for future job has become a challenging problem, faced by university teachers. In addition, it is also one of core issues of higher education reform.

The current mainstream teaching methods for improving students' innovation ability in colleges and universities generally can be divided into four categories: (1) Practical courses, such as class experiments, extra-curricular activities and graduation design projects, have become important components of the teaching system; (2) Scientific research projects, which teachers are required to encourage students to participate in. At the same time, the latest scientific research achievements can be introduced into teaching activities to enhance the course teaching quality; (3)Academic competitions are important supplements to the cultivation of students' innovative ability. These competitions is suitable for students major in electronic information specialty as follows: National Electronic Design Contest, Design Competition of Electronics, ACM Programming Contest, etc..(4) Off-campus project training. Relying on the training bases off campus, students can join the project development team. It is a key way to promote students' professional quality.

These four kinds of methods play a fundamental role in training graduate with creative ideas and practice skills in the higher education. In daily teaching activities, its main participators consist of three parts: teachers, students and engineers. To reach the aim of innovation education, we must develop a collaborative communication mechanism between the participants. However, due to the lack of platform support system for cooperative training operation, the three parties confronted with many challenges in the innovation practice teaching activities. The obstacle to the achievement of the teaching objective exists in the following outstanding problems. 
(1) Teachers are lack of effective means to keep track of the progress of students' extra-curricular practice. In addition, it is also difficult for teachers to carry out online instruction in extra-curricular innovation practice activities.

(2) There is an information gap between teachers on campus, engineers off campus and students. Instructors sometimes are short of efficient communication ways to find some students suitable for a specific scientific project. On the other hand, students are also lack of a software platform to obtain information regarding some projects.

(3) Students and instructors are very hard to cooperatively interact with each other in collaborative practice activities without a support platform.

(4) Without a collaborative platform to support for students' team cooperation activities, students will lose a good chance to improve their team work ability.

To address these issues, this paper introduces the collaborative creative theory and SNS mobile application technology [1][2][7] to construct a collaborative software platform for innovative teaching practice [3], which provides a communication platform and collaborative environment for creative teaching activities. Based on the constructed platform, learners and instructors can carry out online learning and teaching in anytime and anywhere. What's more, the platform is also a learning resources center and a successful case library so as to afford students the opportunity to do some extra-curricular creative activities. In a word, such a collaborative platform can helpful to deepen practice teaching innovation, alleviate the situation of lack of coordination mechanisms, promote the efficiency of cultivation of innovative spirit and ability of students.

\section{Related Work}

How to cultivate students' innovative practice ability is one of the hottest issues of education reform in colleges and universities at domestic and overseas. Specifically, for electronic information science and technology specialty, there are four ways to provide the usual practice of innovation ability training mode. These approaches follow the idea of student-centered learning and students' extracurricular active learning. In order to effectively support the students' innovative practice, some universities have built corresponding network information platforms, which can be categorized as the following three types : (1) Teaching Platform for Experiments (TPE) [4]. The main functions of TPE can be described as an experimental resources warehouse or a virtual experiment simulation platform. (2) Academic Competitions Network Platform (ACNP) [5]. It can provide service for various academic competitions. Specifically, using ACNP, we can convey contests related information, manage the game results and display excellent works. (3) Open Network Teaching Resources Platform (ONTRP). It shares teaching resources and support for offline communication between students in innovation practice activities.

These systems can provide the support for teaching resource sharing and learning interaction for the specific practice teaching mode. However, innovative ability is a comprehensive and multidimensional problem. Hence, these systems are unable to support the innovation practice regarding four categories innovative teaching. Moreover, these traditional teaching platforms are still based on the guideline of the personal practice rather than collaborative practice.

\section{Collaborative platform for innovation teaching}

In this section, a method for construction of the collaborative software platform is described in detail. Based on the SNS technology, we proposed a new teaching pattern for innovation practices. The constructed software platform provides a communication environment for the innovation practice, which facilitates the promotion of learning efficiency.

Three-Tiered System Framework. The collaborative platform consists of three layers : User Interface Layer (UIL), Business Logic Layer (BLL) and Data Service Layer (BSL), as shown in the Figure 1. It can provides a environment for real-time interaction between students, teachers and enterprises, by PC browser or mobile intelligent terminal. 


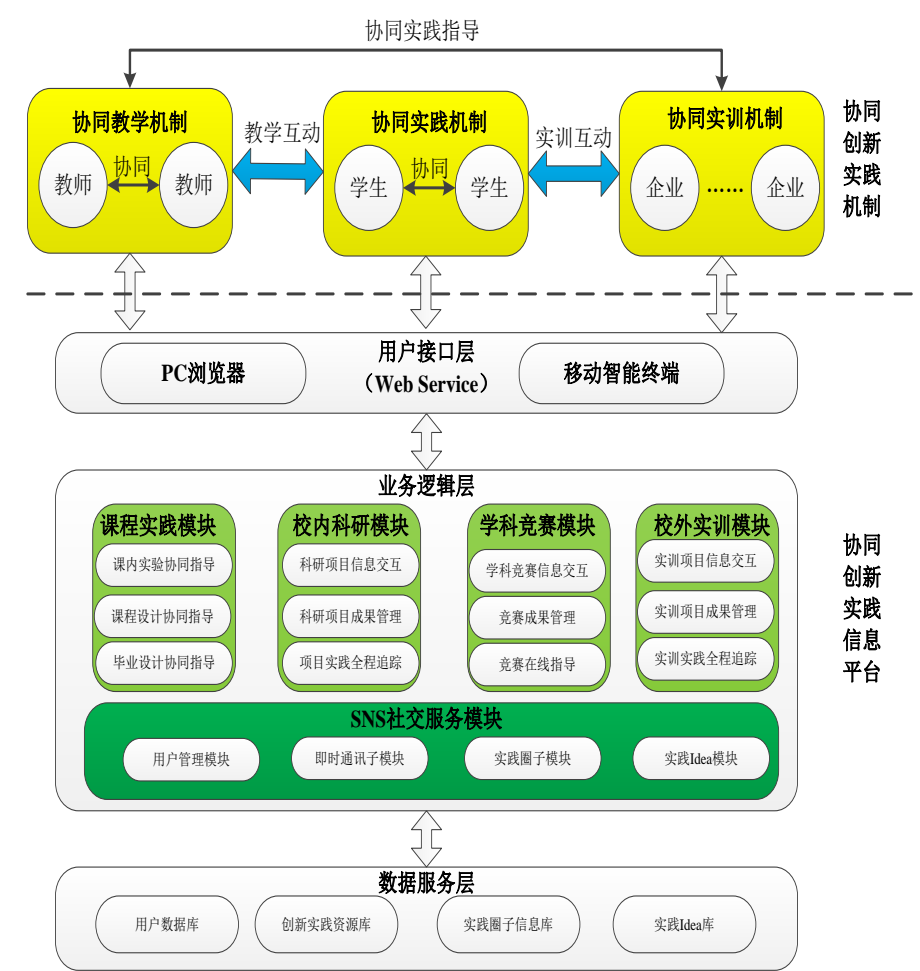

Fig. 1 Three-Tiered System Framework for the Collaborative Platform

The business logic layer is the key component of this platform, which is made up of five function modules as following.

The social networking services module provides a fundamental communication function for collaborative teaching based on SNS technology. It can be separated into four sub-modules: user management, instant communication, practice group and practice idea, respectively.

Practice courses cover the class experiments, course design and graduation design. Relying on practice course module, teachers can take effective real-time tracking and online instruction for students' course practice. Meanwhile, students also obtain an opportunity to communicate with teachers off campus.

Scientific research module help bridge the projects related information gap between teachers and students. In addition, this module also support for tracking progress in projects and share the experiences in the engineering practice.

Academic competitions module facilitates students participation in competitions training. Teachers can share the competition information and organize related competition. Off-campus practice module is similar to the scientific research module. The difference is that it is convenient for students and enterprises to carry out their real-time off-campus interaction. Teachers and enterprises can track practical activities online and effectively manage the innovation practice teaching activity.

Collaborative Platform Implementation. The collaborative platform is constructed based on the client/server architecture, as shown in Figure 2. The server side of the platform is built through customizing an open source social network engine named Elgg [6], which provides the fundamental communication mechanism and function modules for SNS service. For the client side, we also apply an open source framework called Appcan, for quickly developing cross-platform mobile applications using the Html5, CSS and JavaScript. 


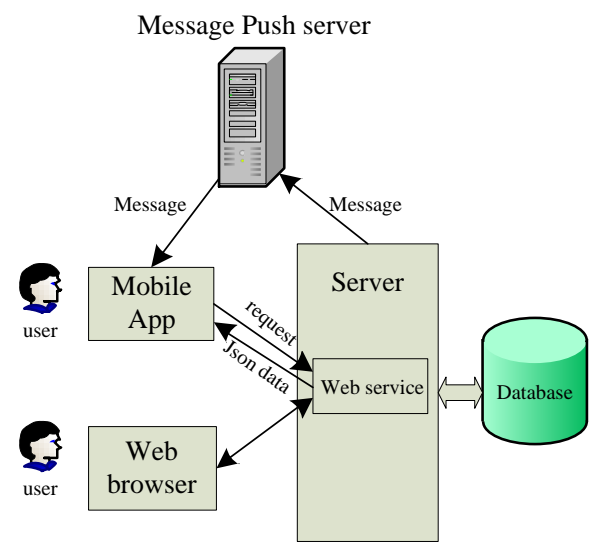

Fig. 2 Client/Server Architecture of the Platform

Through calling the server-side web service, client apps can interact with the server. In addition, based on the third-party push service, the instant communication between mobile apps can be implemented.

System Demonstration. The main screen of the client app is shown in the Figure 3. Using a smart phone installed the app, the three parties in creative practice can communicate with each other to discuss and solve problems, in anytime and anywhere. According to the specific practice activity, we can organize the members into several group, such as student-student group, student-teacher group, and so on. In the innovation practice, teachers and enterprise can guide the innovation practice by the means of real-time tracking practice.
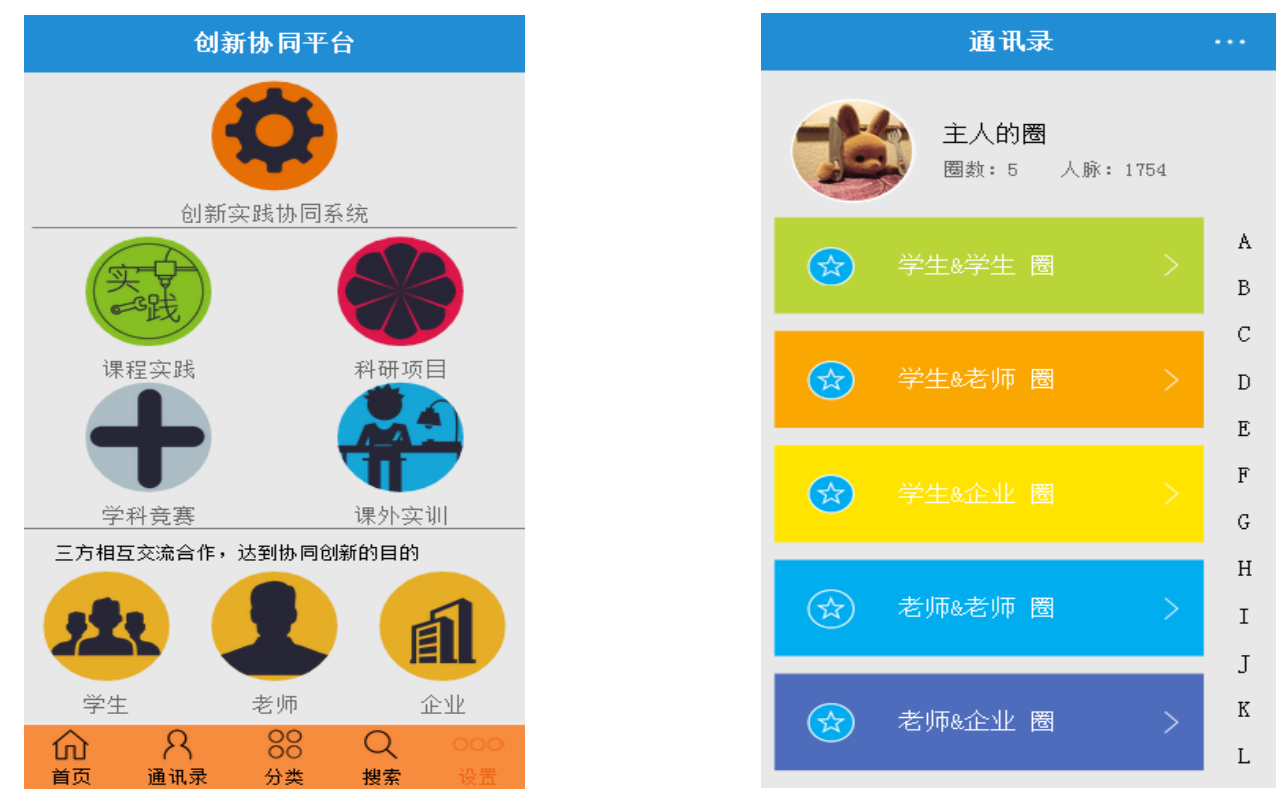

Fig. 3 Client App Screen

As a result, students, teachers and enterprises can implement the collaborative practice based on the proposed collaborative platform. Students can carry out practice project under the guide of the teachers and enterprises.

\section{Conclusion}

The innovative spirit and practical ability is one of the important indicators to evaluate the teaching quality of higher education. A collaborative platform for innovative practice can facilitate improving students' ability for innovation and practice. In this paper, we proposed a method for the construction of a collaborative platform for innovation teaching based on SNS. As a key part of the 
platform, a mobile app provides a support for collaborative practice. With the collaborative platform, everyone in a creative activity can communicate online to carry out the innovative practice organized as a practice group, in anywhere and anytime.

\section{Acknowledgment}

We would like to appreciate the anonymous reviewers for their constructive comments and suggestions to improve the quality of this paper. This work is partially supported by the research fund of Zhejiang provincial education department (No.jg2013051) and education reform fund of Zhejiang Sci-Tech university (zyjh201204).Ministry of Education-Autodesk Inc.professional comprehensive reform project ( Digital Media Technology).

\section{References}

[1] M.S. Lee, Y.E. Son, Design and Implementation of Android-based Cooperative Learning System using Social Network Service, The Journal of Korean Association of Computer Education. 14(2011)71-79.

[2] C. Fuchs, Social networking sites and complex technology assessment, International Journal of E-Politics (IJEP). (2010)92.

[3] E. Kassens-Noor, Twitter as a teaching practice to enhance active and informal learning in higher education: The case of sustainable tweets, Active Learning in Higher Education. 13(2012)9-21.

[4] SUN Q, LI Y, TENG F, et al. Reformation and exploration for the electrician class experiments teaching platform. Laboratory Science, 2013, 2: 054.

[5] C. LIU, X. QI, M. XU, G. WANG, H. ZHANG, Research and Practice of the Reform of Academic Contest System of "Four Layers, Three Degrees", Research and Exploration in Laboratory. 1(2011)033.

[6] Information on http://www.elgg.org.

[7] C. Zhao, M. Cheng, W. Wang, F. Zhang, Construction of informal learning environment model based on SNS, in Knowledge Acquisition and Modeling (KAM), 2010 3rd International Symposium on, 2010, pp. 247-249. 